\title{
Factors Affecting Ultimate Tensile Strength and Impact Toughness of 3D Printed Parts Using Fractional Factorial Design
}

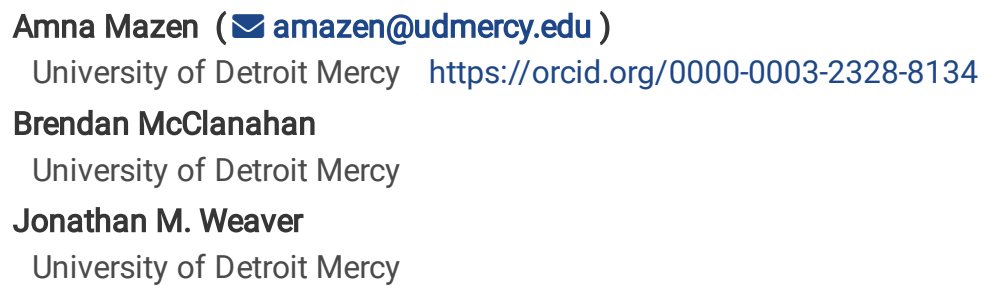

\section{Research Article}

Keywords: Polyactic acid (PLA), Fused Filament Fabrication (FFF), Ultimate tensile strength, Impact toughness, Fractional factorial experiment

Posted Date: July 29th, 2021

DOI: https://doi.org/10.21203/rs.3.rs-613985/v1

License: (c) (1) This work is licensed under a Creative Commons Attribution 4.0 International License. Read Full License

Version of Record: A version of this preprint was published at The International Journal of Advanced Manufacturing Technology on January 4th, 2022. See the published version at https://doi.org/10.1007/s00170-021-08433-0. 


\section{Abstract}

This paper aims to investigate the mechanical properties of spec-imens printed by 3D open-source printers. It discusses the effect of five fac- tors (part/print orientation, layer height, extrusion width, nozzle diameter, and filament temperature) on the ultimate tensile strength and the impact toughness of the 3D-printed samples. A 2 6-1 resolution $V$ fractional factorial experiment was run with the 16 samples printed on a Prusa I3 MK3S in PLA. Tensile strength and impact toughness were tested using Instron 3367 and Tinius Olsen 66 testers, respectively. In analyzing the data, a normal proba- bility plot complimented with ANOVA (Analysis Of Variance) revealed that only part/print orientation was statistically significant at $p=0.05$. Regression equations were used to predict the ultimate tensile strength and the impact toughness as a function of the part/print orientation. Both the toughness re-sponse and the tensile strength response are maximized with horizontal part orientation. Verification experiments have been implemented to validate the adopted regression equations' predictions under different circumstances and the results of those experiments appear to confirm the model.

\section{Introduction}

Fused filament fabrication (FFF) is an additive manufacturing technique that builds parts layer by layer using the extruded thermoplastic filament at low cost [1]. FFF parts are widely used in many fields such as food [2], electronics [3], aerospace [4], automobile [5], etc . The filament is heated up to a semi-solid state and extruded through a heated nozzle to form a layer that is adhered to the previously deposited layers. One of the most widely used polymers for 3D printers is Polylactic acid (PLA) extracted from corn starch, cassava, and sugar. PLA has a high hardness, high strength, low toxicity, and good re- newability. PLA is an eco-friendly material that reduces the consumption of petroleum resources. It's generally easy to print with, odorless, readily avail- able, and affordable. It requires less energy than other materials because it has a low melting temperature [6, ?].

Despite the enormous advantages of 3D printing technology in the produc- tion of complicated parts, its use is limited due to the lack of studies on the mechanical properties of these parts. Tensile strength and Izod impact strength are well-known tests to reveal those properties. Tensile strength testing is a fundamental materials science test, where a sample is subjected to a controlled, increasing tension load until failure [7]. The Izod impact strength test is an American Society for Testing and Materials (ASTM) standard method used to measure the impact resistance (toughness) of materials. Impact toughness represents the amount of energy absorbed during the fracture space[8].

In recent years, some researchers reported studies regarding the mechan-ical properties of 3D-printed PLA parts. Tymrak et al. [9], tested different types of RepRap printers and concluded that RepRap printers have similar tensile strength as commercial printers. Bledzki et al. reported that the tensile strength of injection-molded specimens using PLA filament ranges from 30 to $63 \mathrm{MPa}$ [10]. Tymrak et al. studied the tensile strength of 3D printed samples using ABS and PLA and reported that the average tensile strength is $28.5 \mathrm{MPa}$ and $56.5 \mathrm{MPa}$ for ABS and PLA printed samples, respectively. Tankella et al. [11] also tested the tensile strength for vertical and diagonal print orien- tation for eight materials: ABS, Nylon Bridge, T-Glase, HIPS, polycarbonate, NinjaFlex, nylon 618, and SemiFlex. They concluded that maximum tensile strength of $49.08 \mathrm{MPa}$ is obtained with polycarbonate. The part/print orienta- tion is reported, in the literature review, as one of the most significant factors of the tensile strength of the $3 \mathrm{D}$ printed samples $[12,13, ?, ?, ?]$

\subsection{Fractional Factorial experiment workflow}

Design of Experiment (DOE) methods, such as Fractional factorial experi- ments and full factorial experiments, are used to explore controllable factors on tensile strength and impact toughness of 3D printed parts in this paper. They are statistical methods that can explore the controllable factors on a response efficiently and at a low cost compared to the classical designs [14].

The fractional factorial experiment is recommended over full factorial exper-iment for experiments where high-order interactions can be neglected. If the high-order interactions are negligible, information on the main effects (effect of individual factors) and low-order interactions (low order joint effect of fac- tors may be obtained by considering only a fraction of the original design. Thus, it solves the problem of the exponential increase of the number of ex- perimental runs for a full factorial experiment. Based on the number of factors $k$ in the fractional factorial experiment, $2 k-1$ runs of random order are imple- mented. For each run, the 3D part is printed, tested using the Izod impact tester and tensile strength test, and the corresponding tensile strength and im- pact toughness values are recorded. Data recorded during the experiment is fed into MINITAB $\circledast$ software to be analyzed. Normal Probability Plot (NPP) and Pareto chart are used to identify significant terms (terms that have an effect on the response), whereas Analysis of variance (ANOVA) is used to analyze the effect of those significant terms. The mathematical relation between the responses, tensile strength, and impact toughness in our experiment, and their significant terms is expressed by regression equations. Finally, plots of residual are analyzed to guarantee the complete 
randomness of the experiment. After the main experiment is done, a verification experiment is then implemented to validate the results of the regression model for unseen combinations of factors' levels [15].

\subsection{Contribution}

Since there is no extensive data available about the mechanical properties of parts printed by Prusa I3 MK3S and most home users can not test the mechanical properties of their samples, our experiment comes to satisfy the need to study these properties. A half fractional factorial experiment of five two level factors is used to study their effect on the ultimate tensile strength and impact toughness of samples printed with Prusa I3 MK3S printer using PLA filament. This is the first time that this Design of Experiments strategy has been used in the $3 \mathrm{D}$ printing field to determine the choices of the signif- icant parameters and optimize the tensile strength and impact toughness of $3 \mathrm{D}$ printed parts. The five factors considered in this experiment are part/print orientation, layer height, extrusion width, nozzle diameter, and filament tem- perature. This paper proposes a regression model to describe tensile strength and impact toughness mathematically as a function of their significant terms and predict their values for untested conditions. Verification experiments are also implemented to validate the regression model resulting from this experi- ment.

The remainder of this paper is organized as follows: Section II describes the test sample design, the required physical instruments, the setup of the tensile strength and the impact toughness testers, and the fractional factorial exper-imental design. Section III shows and analyzes the results of this experiment and presents the implementation of verification experiments to validate the prediction of the proposed regression models and finally section IV provides a conclusion and discusses potential future work.

\section{Data And Methods}

\subsection{Sample Design}

The test specimen is designed to allow the implementation of the impact tough- ness and tensile strength testing using the same specimen. Figure 1 shows the engineering drawing of the test specimen with all dimensions in mm. As shown in Figure 1, the left part of the specimen has a standard $45^{\circ}$ notch with $1.6 \mathrm{~mm}$ depth including a $0.25 \mathrm{~mm}$ radius for Izod impact testing. This geometry results in a nominal cross-sectional area of $84 \mathrm{~mm} 2$ for the impact section.

The right part of the specimen shows a narrow section that has a nominal $70 \mathrm{~mm} 2$ cross-sectional area used for the tensile testing. Solidworks is the software used to model the specimen as shown in Figure 2 and saved as ".STL" file. PrusaSlicer software takes the generated STL files as an input and produces the G-code that instructed the printer to make the 3D parts. This software has been used to control the printer settings, such as part orientation, layer height, scan speed, extrusion width, filament temperature, etc.

\subsection{Experimental fractional factorial design}

In this investigation, a fractional factorial design was applied to evaluate the effect of the variation in part orientation $(A)$, layer height $(B)$, extrusion width $(C)$, nozzle diameter $(D)$ and filament temperature $(E)$ on the tensile strength and impact toughness of the 3D printed samples. Those factors are chosen based on our knowledge and experience in 3D printing in addition to literature studies. This experiment comprises five factors with the two levels represented by " 1 " and " +1 " for each factor. Table 1 describes the experiment's factors and their levels in detail. This experiment tests the tensile strength and the impact toughness of each of the 16 printed samples.

Table 1: Factors and its experimental levels 


\begin{tabular}{|llll|}
\hline Factors & Description & Levels \\
Part & Direction of stacked layers across the part & -1 & 1 \\
Orientation $(A)$ & relative to the part geometry & Horizontal & Vertical \\
Layer & Height of the layer (step) that is stacked to & & \\
Height $(B)$ & form the part & $0.15 \mathrm{~mm}$ & $0.25 \mathrm{~mm}$ \\
Extrusion Width $(C)$ & Width of the line extruded by the printer that & & $150^{2}$ \\
& forms the layers of the part. This is a percentage of the nozzle diameter & $100 \%$ & $0.6 \mathrm{~mm}$ \\
Nozzle & Diameter of orifice of the printer nozzle & $0.4 \mathrm{~mm}$ & \\
Diameter $(D)$ & & $208^{\circ} \mathrm{C}$ & $217^{\circ} \mathrm{C}$ \\
Filament & Temperature of the filament while passing & & \\
Temperature $(E)$ & through the extruder nozzle & & \\
\hline
\end{tabular}

The fractional factorial experimental design is a 1 fraction of a 25 (32) full factorial design by conducting only 16 runs in this experiment. Since only half of the total full-factorial runs is used in a half-fractional factorial experiment, a design generator is used to choose this fraction with some desirable proper- ties. The desirable properties are the balance and independence between the factors. Balance in a factor refers to an equivalent number of the two levels (each factor has 8 of the two levels ' -1 ' and ' +1 ' in our experiment), whereas the independence between factors refers to zero dot product between any two factors as shown in Table 2 . The best design generator in half fractional fac- torial is the highest-order one to manage aliasing terms. In this experiment, the levels of the first four factors $(A, B, C$ and $D$ ) are constructed as the all possible combinations of them (full factorial design of four factors) and the last factor ( $E$ )'s levels are generated using the design generator $E=A B C D$ as shown in Table 2 to guarantee the desirable properties. This construction refers to resolution $\mathrm{V}$ where resolution $\mathrm{V}$ designs provide estimates of all main effects which are not aliased with any terms containing less than four fac- tors. In resolution $V$ designs, two-factor interactions are not aliased with main effects or other two-factor interactions but may be aliased with three-factor interactions. The resolution of an experiment identifies the degree of terms to which the main effects are (aliased) and is expressed with Roman letters $(I, I I, I I I, I V, V, V I, \ldots)$. Based on the sparsity of effects principle, we will assume three factors and higherorder interactions are negligible.

\subsection{Test setup}

The required physical elements to run this experiment are a FFF 3D printer, PLA material, an Izod impact tester, an Instron tensile tester, and calipers for gauging the actual dimensions for the tested samples. Additionally, MINITAB® software was used in the analysis of the data. All machines used in this paper are provided by the University of Detroit Mercy (UDM), MI, USA. Original Prusa i3 MK3S, Figure 3, is the FFF 3D printer model used to print all the test samples in this experiment. The precision (tolerance) of an original Prusa printer is $0.1 \mathrm{~mm}$ on the $Z$-axis and $0.3 \mathrm{~mm}$ on $X$ and $Y$. The Instron 3367 tensile testing machine, shown in Figure 4, has been used to perform tensile tests in this experiment. This machine was equipped with a $20 \mathrm{KN}$ load cell to measure the tensile strength of the 3D printed parts. The measurement data was controlled, monitored, and recorded using "Series IX/s" Instron software. The Tinius Olsen 66, shown in Figure 5 , has been used to implement the impact toughness test in this experiment. It has a pivoting arm that is raised to a specific height to maintain constant potential energy and then released to hit and break a notched sample. The angle to which the arm swings is indicative of energy lost in breaking the specimen which represents the impact resistance. Original Prusa i3 MK3S used the same ".STL" file with different slicing settings to print all 16 samples in the randomized "Run Order" order shown in Table 2. Some printing settings are kept constant for all samples such as $60^{\circ} \mathrm{C}$ bed temperature, $100 \%$ infill percentage, and grey PLA filament material. In this experiment, the 3D parts are printed either horizontally or vertically. Fig- ure 6 shows the difference between the horizontal and vertical printed samples. In the vertical printing of the left sample, the square base is firstly printed and other layers are then accumulated vertically, whereas the sophisticated base is printed first for the horizontal right sample. The mass of every sample is mea- sured using a scale to make sure that there is no interior under-extrusion. All samples weighed approximately 14 grams which suggest that each extrusion is good. 
The whole Instron machine with a close up of a sample in the test setup clamped between the jaws of the tensile strength tester is shown in Figure 4. The tensile strength tester, used in this experiment, applied a $20 \mathrm{KN}$ tensile load on each specimen at $5 \mathrm{~mm} / \mathrm{min} \mathrm{cross}-\mathrm{head}$ speed. Instron tester is used to measure the maximum force that specimen can withstand before failure in Newtons as shown in Table 3. This force is then divided by the narrow cross-sectional area to calculate the ultimate tensile strength (UTS) of each specimen. The Tinius Olsen 66 Izod impact resistance tester, Figure 5, is used for this experiment with a pivoting arm raised to a specific height (to maintain constant potential energy) and swings down to hit and break a notched sample. The energy absorbed by the sample is measured from the height the arm swings after hitting the sample. The impact resistance tester measures inch-pounds (energy) absorbed by breaking the specimen at the notched cross-sectional area. Toughness $(\mathrm{J} / \mathrm{m} 2)$ is then calculated by multiplying the absorbed energy (in-lbs) by 0.112984825 to be converted into joules and then divided by the notched cross-sectional area. The recorded tensile force $(\mathrm{N})$, impact resistance (in-lbs), the printing time for each specimen are shown in Table 3. It also includes the measured length and width in millimeters of the cross-sectional area used in the tensile and notched Izod tests for each sample.

Table 2: Experimental fractional factorial design matrix

\begin{tabular}{|c|c|c|c|c|c|c|c|c|}
\hline $\begin{array}{l}\text { Std } \\
\text { order }\end{array}$ & $\begin{array}{l}\text { Run } \\
\text { order }\end{array}$ & $A$ & B & C & D & $E$ & $\begin{array}{l}\text { Tensile } \\
\text { Strength (MPa) }\end{array}$ & Toughness $(\mathrm{J} / \mathrm{m} 2)$ \\
\hline 1 & 12 & 1 & 1 & 1 & 1 & 1 & 25.61 & 1344 \\
\hline 2 & 15 & 1 & 1 & 1 & -1 & -1 & 24.33 & 2576 \\
\hline 3 & 14 & 1 & 1 & -1 & 1 & -1 & 22.94 & 1955 \\
\hline 4 & 10 & 1 & 1 & -1 & -1 & 1 & 13.57 & 1306 \\
\hline 5 & 7 & 1 & -1 & 1 & 1 & -1 & 27.66 & 2668 \\
\hline 6 & 16 & 1 & -1 & 1 & -1 & 1 & 23.10 & 1284 \\
\hline 7 & 5 & 1 & -1 & -1 & 1 & 1 & 21.70 & 2003 \\
\hline 8 & 6 & 1 & -1 & -1 & -1 & -1 & 29.34 & 1338 \\
\hline 9 & 13 & -1 & 1 & 1 & 1 & -1 & 56.89 & 3488 \\
\hline 10 & 8 & -1 & 1 & 1 & -1 & 1 & 55.04 & 3198 \\
\hline 11 & 3 & -1 & 1 & -1 & 1 & 1 & 51.78 & 3298 \\
\hline 12 & 9 & -1 & 1 & -1 & -1 & -1 & 59.83 & 3828 \\
\hline 13 & 11 & -1 & -1 & 1 & 1 & 1 & 65.49 & 3826 \\
\hline 14 & 1 & -1 & -1 & 1 & -1 & -1 & 47.67 & 3899 \\
\hline 15 & 2 & -1 & -1 & -1 & 1 & -1 & 57.49 & 2603 \\
\hline 16 & 4 & -1 & -1 & -1 & -1 & 1 & 56.96 & 3880 \\
\hline
\end{tabular}

Table 3: Printed samples recorded measurements 


\begin{tabular}{|c|c|c|c|c|c|c|c|}
\hline \multirow[t]{2}{*}{ Run order } & \multirow[t]{2}{*}{ Print time (mins) } & \multicolumn{2}{|c|}{ Tensile Cross Section } & \multicolumn{2}{|c|}{ Impact Cross Section } & \multirow[t]{2}{*}{ Tensile force $(\mathrm{N})$} & \multirow[t]{2}{*}{ Impact resistance (in-lb) } \\
\hline & & $\begin{array}{l}\text { Length } \\
(\mathrm{mm})\end{array}$ & $\begin{array}{l}\text { Width } \\
(\mathrm{mm})\end{array}$ & $\begin{array}{l}\text { Length } \\
(\mathrm{mm})\end{array}$ & $\begin{array}{l}\text { Width } \\
(\mathrm{mm})\end{array}$ & & \\
\hline 12 & 71 & 9.83 & 6.88 & 9.81 & 8.57 & 1732 & 1 \\
\hline 15 & 106 & 9.95 & 6.97 & 9.98 & 8.79 & 1687 & 2 \\
\hline 14 & 106 & 9.93 & 6.98 & 10.07 & 8.61 & 1590 & 1.5 \\
\hline 10 & 163 & 10.03 & 7.04 & 10.06 & 8.6 & 958 & 1 \\
\hline 7 & 114 & 9.76 & 6.85 & 9.87 & 8.58 & 1849 & 2 \\
\hline 16 & 171 & 9.86 & 6.87 & 10 & 8.8 & 1565 & 1 \\
\hline 5 & 171 & 9.92 & 6.94 & 9.93 & 8.52 & 1494 & 1.5 \\
\hline 6 & 258 & 9.95 & 6.98 & 10.02 & 8.43 & 2038 & 1 \\
\hline 13 & 30 & 9.98 & 7.05 & 10.11 & 8.7 & 4003 & 2.7 \\
\hline 8 & 47 & 9.95 & 7.29 & 9.99 & 8.84 & 3992 & 2.5 \\
\hline 3 & 74 & 9.98 & 6.92 & 9.97 & 8.59 & 3940 & 2.5 \\
\hline 9 & 68 & 9.97 & 7.12 & 10.05 & 8.81 & 4247 & 3 \\
\hline 11 & 50 & 10.06 & 6.95 & 10.23 & 8.66 & 4579 & 3 \\
\hline 1 & 45 & 9.88 & 6.91 & 9.89 & 8.79 & 4144 & 3 \\
\hline 2 & 71 & 9.96 & 6.9 & 9.99 & 8.69 & 3951 & 2 \\
\hline 4 & 107 & 10.04 & 7.01 & 10.03 & 8.71 & 4009 & 3 \\
\hline
\end{tabular}

\section{Results And Discussion}

Each combination of different levels of factors is used to setup the 3D printer to print the 16 samples. Each 3D printed sample is then exposed to the Izod impact test using the Tinius Olsen tester followed by the tensile strength test using Instron tester in this experiment. The 3D printed samples' tensile strength was tested using an Instron tensile test machine with a hydraulic linear actuator and a $20 \mathrm{KN}$ load cell. The impact toughness of the parts was measured using an Izod Impact testing machine. Figure 7 shows all the broken samples after the tensile strength and the impact toughness testing. Exper-imental data, obtained from fractional factorial design runs, were analyzed using the statistical software package MINITAB® 19.

\subsection{Ultimate tensile strength Data Analysis}

The ultimate tensile strength (UTS) is defined as the maximum tensile load a part can withstand before failure divided by its crosssectional area. During the tensile test, 16 specimens have been stretched till failure and their cor- responding data are recorded in Table 3. The tensile strength (MPa) of each part was calculated with Microsoft Excel based on the recorded tensile values and measured dimensions included in Table 3 and the results are shown in Ta- ble 2. Because a single replicate (one experiment with 16 runs) of a fractional factorial provides no direct measure of the error to perform ANOVA directly, a Normal Probability Plot (NPP) and Pareto chart are used to reveal significant effects. Significant terms are the terms that doesn't belong to the straight line in NPP or exceed the threshold in Pareto chart. Part orientation is the only term that doesn't belong the straight line in Normal Probability Plot (NPP) of effects shown in Figure 8a and exceeds the threshold in Pareto chart in our experiment as shown in Figure 9a. Based on the Normal Probability Plot (NPP) of effects and Pareto chart, part orientation $(A)$ is the only significant factor at $5 \%$ significance level for the ultimate tensile strength.

Analysis of Variance (ANOVA) indicates whether the obtained results hap- pened by chance or not. If the p-value of a term is less than the significance level, the term will be significant. The p-value of a term is calculated based on the F-distribution value computed by the division of the adjusted mean square of the term over the adjusted mean square of error. Adjusted mean squares (Adj MS) are computed by the division of 'Adj SS' over the degrees of freedom. The degree of freedom is ' 1 ' for all terms in a half fractional exper- iment with two levels. Analysis of Variance (ANOVA) of the UTS, included in Table 4, shows that print orientation factor $(A)$ is significant and with the 
confidence of virtually $100 \%$ affects tensile strength, assuming all apparently insignificant effects represent the error. The regression equation of the UTS

$(Y 1)$ is shown in equation (1) where the constant term the average of values in column "Tensile Strength (MPa)" and the effect of factor $A$ is the average of the product of values in column " $A$ " by values in column "Tensile Strength (MPa)" in Table 2. Based on this equation, the maximum value of ultimate tensile strength (UTS) is $56.39 \mathrm{MPa}$, obtained for horizontal part orientation $(A=-1)$. This result confirms those reported for PLA [9].

$Y 1=39.96-16.43 * A$

Residual analysis check that the experiment is implemented completely randomized. Normal Probability Plot of residuals, the plot of residuals versus the fitted values, and observation order were checked to make sure that the model's assumptions are satisfied. Normal Probability Plot of residuals, Figure 10, shows that the error distribution is normal as residuals are adjusted to an approximately straight line. The plot of residuals versus the fitted values of the UTS, Figure 11a, shows no pattern which indicating independence of the residuals seems reasonable. The plot of residuals versus observation order, Figure 11b, proves nothing unexpected affected residuals over time (run order).

Table 4: Analysis of variance (ANOVA) for tensile strength

\begin{tabular}{lccccc} 
Source & DF & Adj SS & Adj MS & F-Value & P-Value \\
\hline Model & 1 & 4319.92 & 4319.92 & 170.59 & 0.000 \\
\hline Linear & 1 & 4319.92 & 4319.92 & 170.59 & 0.000 \\
\hline A & 1 & 4319.92 & 4319.92 & 170.59 & 0.000 \\
\hline Error & 14 & 354.5 & 25.32 & & \\
\hline Total & 15 & 4674.4 & & &
\end{tabular}

\subsection{Impact toughness Data Analysis}

Material's toughness measures a material's ability to absorb energy and plas- tically deform without fracturing. Part orientation $(A)$ is the only significant factor for impact toughness depending on Normal Probability Plot (NPP) of effects in Figure 8b and Pareto chart in Figure $9 \mathrm{~b}$ with a $5 \%$ significance level. In order to investigate some of the next largest effects, the plot was made with a $10 \%$ significance level. With $10 \%$ significance level, $A, B E, C E$ are signif- icant but regression model with those terms and their main effect $B, C$, $E$ predicts the impact toughness of verification samples incorrectly. Thus, part orientation $(A)$ appears to be the only significant factor based on several con- firmation runs performed. Other terms may have been dismissed due to the poor resolution of the Tinius tester. The regression equation of impact tough- ness $Y 2$ is equation (2) with constant term and effect of factor $A$ computed in the same way as tensile strength analysis. The maximum toughness of 3D printed part ( $3629 \mathrm{~J} / \mathrm{m} 2$ ) occurs at $A=-1$ (horizontal part orientation).

$Y 2=2719-910 * A$

From the analysis of Variance of the impact toughness of the 3D-printed samples, pooling insignificant terms to error, shown in Table 5, part orien- tation is statistically significant at $95 \%$ confidence interval as $p$-value is less than 0.05 . Residual analysis is done to ensure that the error is normally and independently distributed with constant variance. NPP of residuals in Figure

Table 5: Analysis of variance (ANOVA) for impact toughness

\begin{tabular}{llllll} 
Source & DF & Adj SS & Adj MS & F-Value & P-Value \\
\hline Model & 1 & 13238682 & 13238682 & 39.72 & 0.000 \\
\hline Linear & 1 & 13238682 & 13238682 & 39.72 & 0.000 \\
\hline A & 1 & 13238682 & 13238682 & 39.72 & 0.000 \\
\hline Error & 14 & 4665818 & 333273 & & \\
\hline Total & 15 & 17904500 & & &
\end{tabular}


12 shows a roughly linear trend, indicating that the residuals can be consid- ered to be normally distributed. The plot of residuals of the toughness versus the fitted values, Figure 13a, shows no relationship between the size of the residuals and the fitted values indicating that we can assume independence and constant variance. The plot of the impact toughness's residuals versus observation order, Figure 13b, doesn't show any concern about unexpected issues that may affect the validity of the results.

\subsection{Verification experiments}

Two nominally identical specimens for the two verification experimental runs are built resulting in four test specimens, two for the vertical part orientation and the other two for the horizontal part orientation. Those four samples were used to validate the model's prediction for the ultimate tensile strength and material toughness for an unseen 3D printed specimen. Repetition was used to decrease error variance and to avoid possibly missing data due to periodic unexpected problems in the tensile tester. Sometimes, the tensile strength tester suffers from a sudden increase in tensile load resulting in breaking the sample without recording the associated load. This problem prevented one of the two vertical verification samples from being included as its associated

Table 6: Verification experiment recorded measurements

\begin{tabular}{|c|c|c|c|c|c|c|c|}
\hline \multirow[t]{4}{*}{ Std order } & \multirow[t]{4}{*}{ Run order } & \multirow{2}{*}{\multicolumn{2}{|c|}{$\begin{array}{l}\text { Tensile } \\
\text { Cross Section }\end{array}$}} & \multirow{2}{*}{\multicolumn{2}{|c|}{$\begin{array}{l}\text { Impact } \\
\text { Cross Section }\end{array}$}} & \multirow[t]{4}{*}{ Tensile force $(\mathrm{N})$} & \multirow[t]{4}{*}{ Impact Resistance (in.lbs) } \\
\hline & & & & & & & \\
\hline & & \multirow{2}{*}{$\begin{array}{l}\text { Length } \\
(\mathrm{mm})\end{array}$} & \multirow{2}{*}{$\begin{array}{l}\text { Width } \\
(\mathrm{mm})\end{array}$} & \multirow{2}{*}{$\begin{array}{l}\text { Length } \\
(\mathrm{mm})\end{array}$} & \multirow{2}{*}{$\begin{array}{l}\text { Width } \\
(\mathrm{mm})\end{array}$} & & \\
\hline & & & & & & & \\
\hline 1 & 1 & 9.83 & 6.91 & 9.88 & 8.71 & 1739 & 1 \\
\hline 2 & 3 & 10.13 & 6.86 & 10.13 & 8.66 & 3943 & 2.5 \\
\hline 3 & 4 & 9.80 & 6.93 & 9.88 & 8.69 & Fail & 1 \\
\hline 4 & 2 & 10.03 & 6.90 & 10.11 & 8.79 & 3909 & 3.5 \\
\hline
\end{tabular}

Table 7: Tensile strength verification experimental data

\begin{tabular}{llllll}
$\begin{array}{l}\text { Part } \\
\text { orientation }\end{array}$ & $\begin{array}{l}\text { Recorded } \\
\text { value }(\mathrm{MPa})\end{array}$ & $\begin{array}{l}\text { Model predicted } \\
\text { value }(\mathrm{MPa})\end{array}$ & $\begin{array}{l}\text { Standard } \\
\text { deviation }(\mathrm{MPa})\end{array}$ & $\begin{array}{l}\text { Low } \\
\text { limit (MPa) }\end{array}$ & $\begin{array}{l}\text { High } \\
\text { limit (MPa) }\end{array}$ \\
\hline Vertical & 25.61 & 23.53 & 5.03 & 18.5 & 28.56 \\
\hline Horizontal & 56.61 & 56.39 & & 51.36 & 61.42
\end{tabular}

Table 8: Toughness verification experimental data

\begin{tabular}{|c|c|c|c|c|c|}
\hline Part orientation & ${ }^{\text {Recorded value }(\mathrm{J} / \mathrm{m} 2}$ & ${ }^{\text {Model predicted value }(\mathrm{J} / \mathrm{m} 2}$ & $\int^{\text {Standard deviation }(\mathrm{J} / \mathrm{m} 2}$ & )$^{\text {Low } \operatorname{limit}(\mathrm{J} / \mathrm{m} 2}$ & $\begin{array}{l}\text { High limit } \\
(\mathrm{J} / \mathrm{m} 2)\end{array}$ \\
\hline Vertical & 1314 & 1809 & \multirow[t]{2}{*}{577.3} & 1231.7 & 2386.3 \\
\hline Horizontal & 3834 & 3629 & & 3051.7 & 4206.3 \\
\hline
\end{tabular}

value was not recorded. The response (recorded value) is the average of the two recorded measurements for each experimental run.

The standard order of each experiment and the measurements of length and width in $\mathrm{mm}$ for the tensile and impact cross-sectional area are recorded in Table 6. Each sample is subjected to the Izod impact test to measure the impact resistance followed by the tensile test to measure the tensile force with "run" order and experimental data is shown in Table 6. Similarly to main experiment, the tensile force and the impact resistance are used to calculate the ultimate tensile strength and the material impact toughness, respectively. The average of values obtained by practical tensile strength and toughness testing of the two specimens as shown in Table 7 and 8 , respectively. The regression equations (discussed earlier) are then used to predict the tensile strength and the impact toughness associated with the specific orientation as shown in the "Model predicted value" column in Table 7 and 8, respectively. The standard deviation obtained from MINITAB® analysis is used to calculate the low and high limits of the model predicted values. The low and high limits are calculated by the subtraction and addition of the standard deviation value from the model predicted value, respectively. 
The summarized verification results for the tensile strength and the impact toughness models are shown in Table 7 and Table 8, respectively. The lab measurements lie between the low and high limits of the predicted values by the models for the tensile strength and the material toughness. For example, the average UTS obtained by the verification experiment for horizontal part orientation ( $56.61 \mathrm{MPa})$ is only $0.39 \%$ greater than the predicted value $(56.39 \mathrm{MPa})$ in Table 7 and well \pm 2 standard deviation. These results confirm the effectiveness of regression equations to predict experimental results accurately and enhance its validation to predict the ultimate tensile strength and the impact toughness for untested 3D printed parts.

\section{Conclusion}

This experiment investigates the mechanical properties of the 3D printed sam- ples by implementing the tensile strength test and the lzod impact test. A frac- tional factorial experiment with five process factors was implemented. Based on the experimental results, the only significant factor identified in this exper- iment is the part orientation. Those results emphasize the fact that to get a significant change in the tensile strength or toughness of a 3D-printed sample, there is no need to change nozzle diameter, layer size, extrusion width, or filament temperature, just change part orientation. The other parameters may be chosen to minimize the print time with no effect on the tensile strength or impact toughness. Higher tensile strength and impact toughness have been obtained at horizontal part orientation irrespective of the level of the other four process factors. 3D parts printed with horizontal part orientation also takes less time than vertical ones. Verification experiments are implemented in the same procedure of main experiment with untested combination of fac- tors' levels. The recorded values of verification experiments for the tensile strength and impact toughness model lie within the standard deviation of the predicted values. The reliability of the obtained regression equations was vali- dated by comparing the established experimentally UTS and impact toughness with the corresponding predicted values. This proves the effectiveness of the model regression equations and confirms that the model can predict correctly the response for future 3D-printed parts under similar conditions.

This preliminary study has some limitations. There was a significant error introduced by the poor resolution of the Izod Impact tester used and the oversized $(20 \mathrm{KN})$ load cell used in the tensile strength tester. The Izod Impact tester scale used had a resolution of 0.5 in Ibs which was about $23.9 \%$ of the average impact response measured. The $20 \mathrm{KN}$ load cell used in the tensile tester has not had a verified calibration and the average maximum tensile force measured with this cell for the 16 samples was $2861 \mathrm{~N}$. This average value is within the generally accepted $10 \%$ to $90 \%$ of the nominal rating minimum accurate range of the $20 \mathrm{KN}$ load cell (greater than $2000 \mathrm{~N}$ ), but 7 of the 16 responses were measured to be below the $2000 \mathrm{~N}$ threshold. Thus, a $5 \mathrm{KN}$ load cell would be recommended for follow-on work.

In a future study, calibration across the expected range of the load cell should be done to verify its accuracy in the range of the test measurements, or another reliable measurement method should be employed in a future test. Finally, a proper gauge R\&R ought to be done before such an experiment to determine how much variance is due to the measurement process rather than the simple variation in response and other noise factors.

\section{Declarations}

\section{Funding}

There are no funding authorities

\section{Conflict of interest}

The authors declare that they have no conflict of interest.

\section{Availability of data and material}

The data that support the findings of this study are available in Table 2

\section{Code availability}

Code for data cleaning and analysis is provided as part of the replication pack- age. It is available and will be uploaded to the [JOURNAL REPOSITORY] once the paper has been conditionally accepted.

\section{Ethics approval}

Not applicable 


\section{Consent to participate}

Not applicable

\section{Consent for publication}

Not applicable

\section{References}

1.Bikas, H., Stavropoulos, P., and Chryssolouris, G., 2016. "Additive manufacturing methods and modelling approaches: a critical review". The International Journal of Advanced Manufacturing Technology, 83(1-4), pp. 389-405.

2.Lipton, J. I., Cutler, M., Nigl, F., Cohen, D., and Lipson, H., 2015. "Additive manufac- turing for the food industry". Trends in food science \& technology, 43(1), pp. 114-123.

3.Tan, H. W., An, J., Chua, C. K., and Tran, T., 2019. "Metallic nanoparticle inks for 3d printing of electronics". Advanced Electronic Materials, 5(5), p. 1800831.

4.Murr, L. E., 2016. “Frontiers of 3d printing/additive manufacturing: from human organs to aircraft fabrication”. Journal of Materials Science \& Technology, 32(10), pp. 987- 995.

5.Talagani, M., DorMohammadi, S., Dutton, R., Godines, C., Baid, H., Abdi, F., Kunc, V., Compton, B., Simunovic, S., Duty, C., et al., 2015. “Numerical simulation of big area additive manufacturing (3d printing) of a full size car”. Sampe Journal, 51(4), pp. 27-36.

6.Pivsa-Art, W., Chaiyasat, A., Pivsa-Art, S., Yamane, H., and Ohara, H., 2013. "Prepa- ration of polymer blends between poly (lactic acid) and poly (butylene adipate-co- terephthalate) and biodegradable polymers as compatibilizers”. Energy Procedia, 34, pp. 549-554.

7.Davis, J. R., 2004. Tensile testing. ASM international.

8.Wang, L., and Gardner, D. J., 2017. "Effect of fused layer modeling (flm) processing parameters on impact strength of cellular polypropylene". Polymer, 113, pp. 74-80.

9.Tymrak, B., Kreiger, M., and Pearce, J. M., 2014. "Mechanical properties of compo- nents fabricated with open-source 3-d printers under realistic environmental conditions". Materials \& Design, 58, pp. 242-246.

10.Bledzki, A. K., Jaszkiewicz, A., and Scherzer, D., 2009. “Mechanical properties of pla composites with man-made cellulose and abaca fibres". Composites Part A: Applied science and manufacturing, 40(4), pp. 404-412.

11.Tanikella, N. G., Wittbrodt, B., and Pearce, J. M., 2017. "Tensile strength of commercial polymer materials for fused filament fabrication $3 d$ printing". Additive Manufacturing, 15, pp. 40-47.

12.Liu, X., Zhang, M., Li, S., Si, L., Peng, J., and Hu, Y., 2017. "Mechanical property parametric appraisal of fused deposition modeling parts based on the gray taguchi method". The International Journal of Advanced Manufacturing Technology, 89(5), pp. 2387-2397.

13.Pei, E., Lanzotti, A., Grasso, M., Staiano, G., and Martorelli, M., 2015. "The impact of process parameters on mechanical properties of parts fabricated in pla with an open- source 3-d printer". Rapid Prototyping Journal.

14.Gunst, R. F., and Mason, R. L., 2009. “Fractional factorial design”. Wiley Interdisci- plinary Reviews: Computational Statistics, 1(2), pp. 234-244.

15.Montgomery, D. C., 2017. Design and analysis of experiments. John wiley \& sons.

\section{Figures}




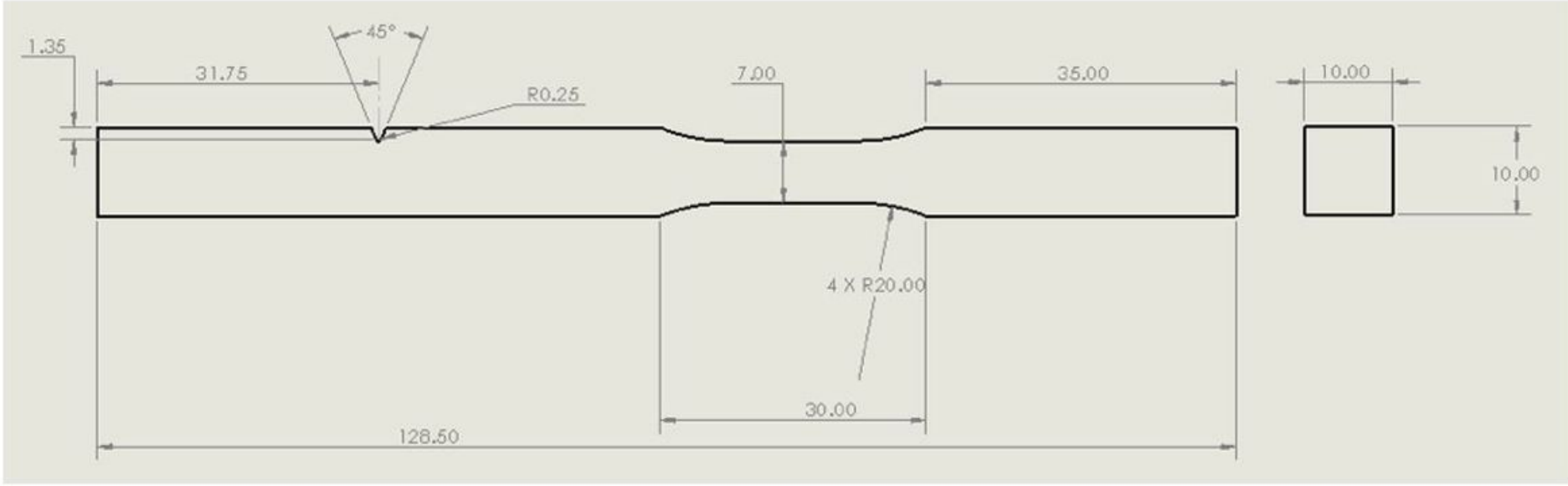

\section{Figure 1}

Engineering drawing of test specimen

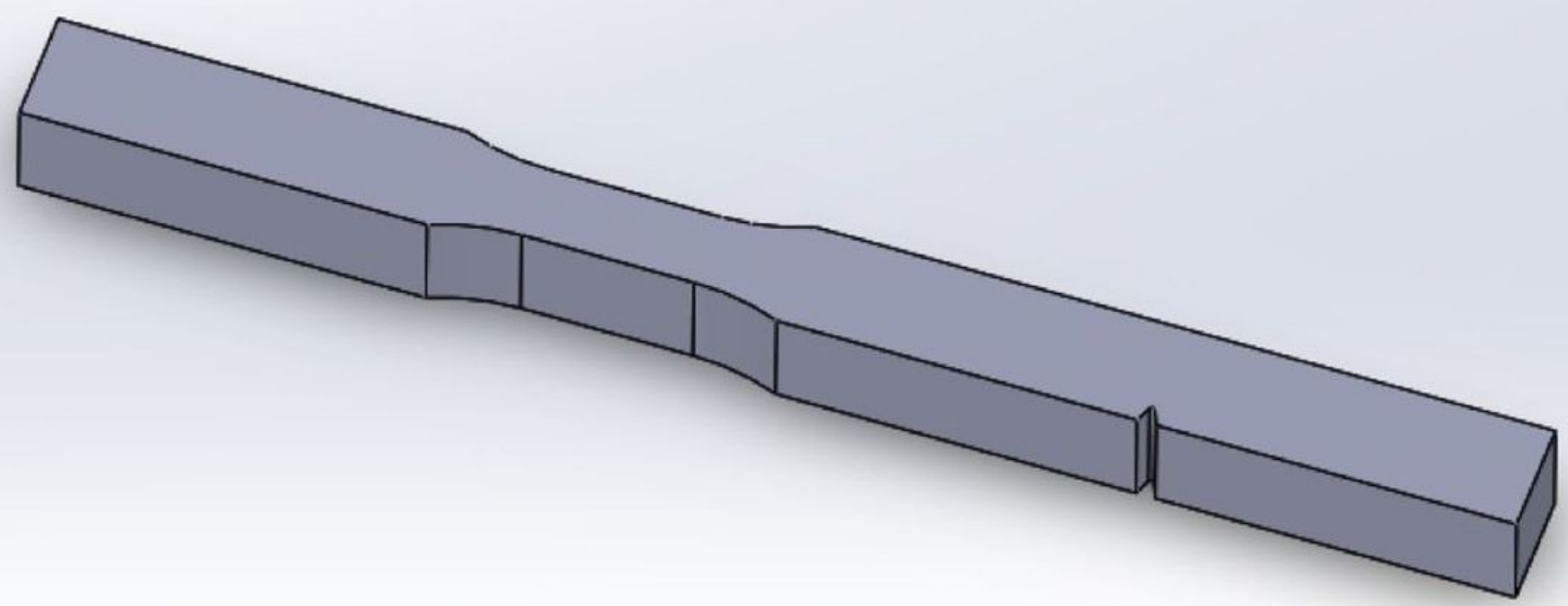

\section{Figure 2}

Solidworks 3D model of test specimen 


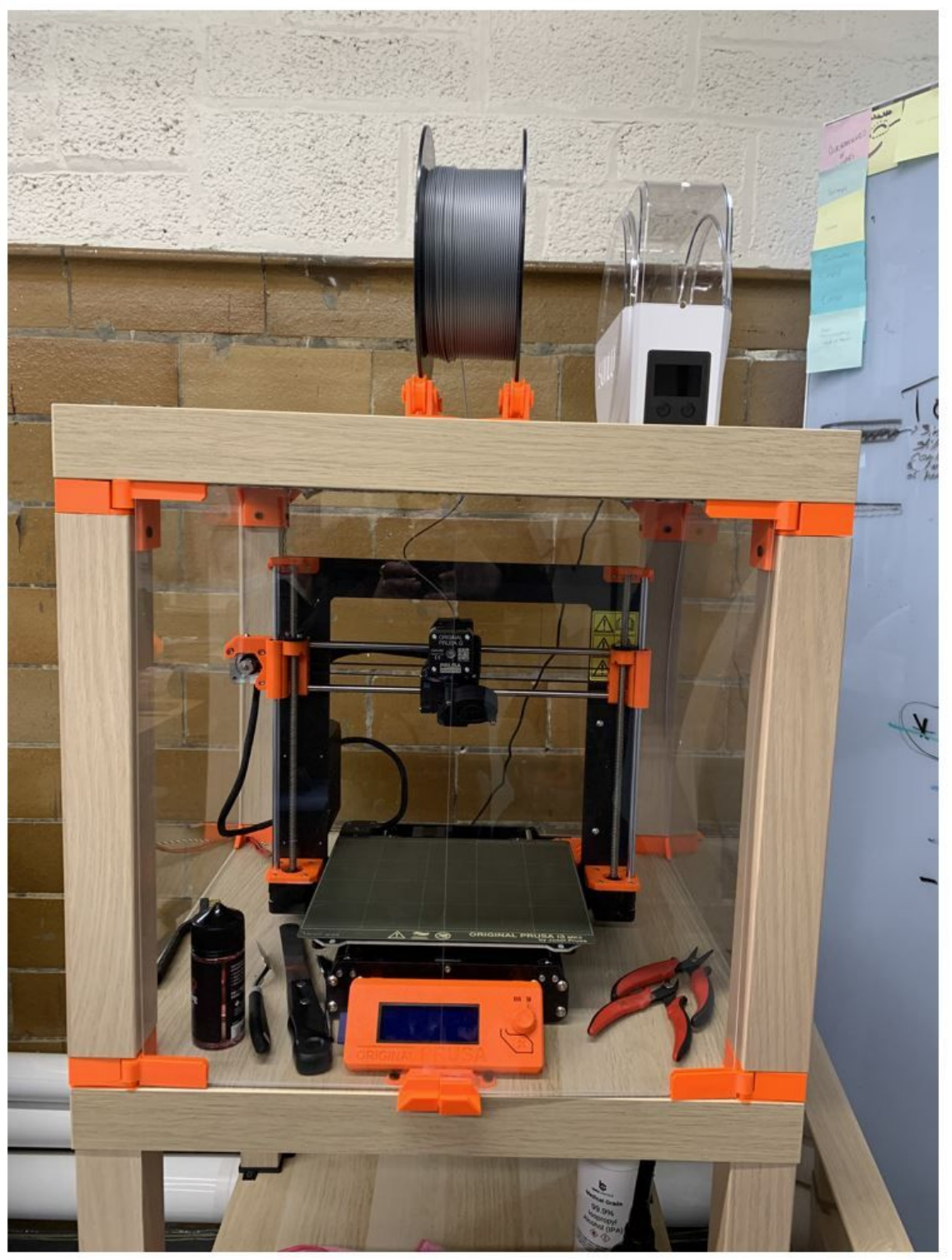

Figure 3

Original Prusa i3 MK3S 3D printer 


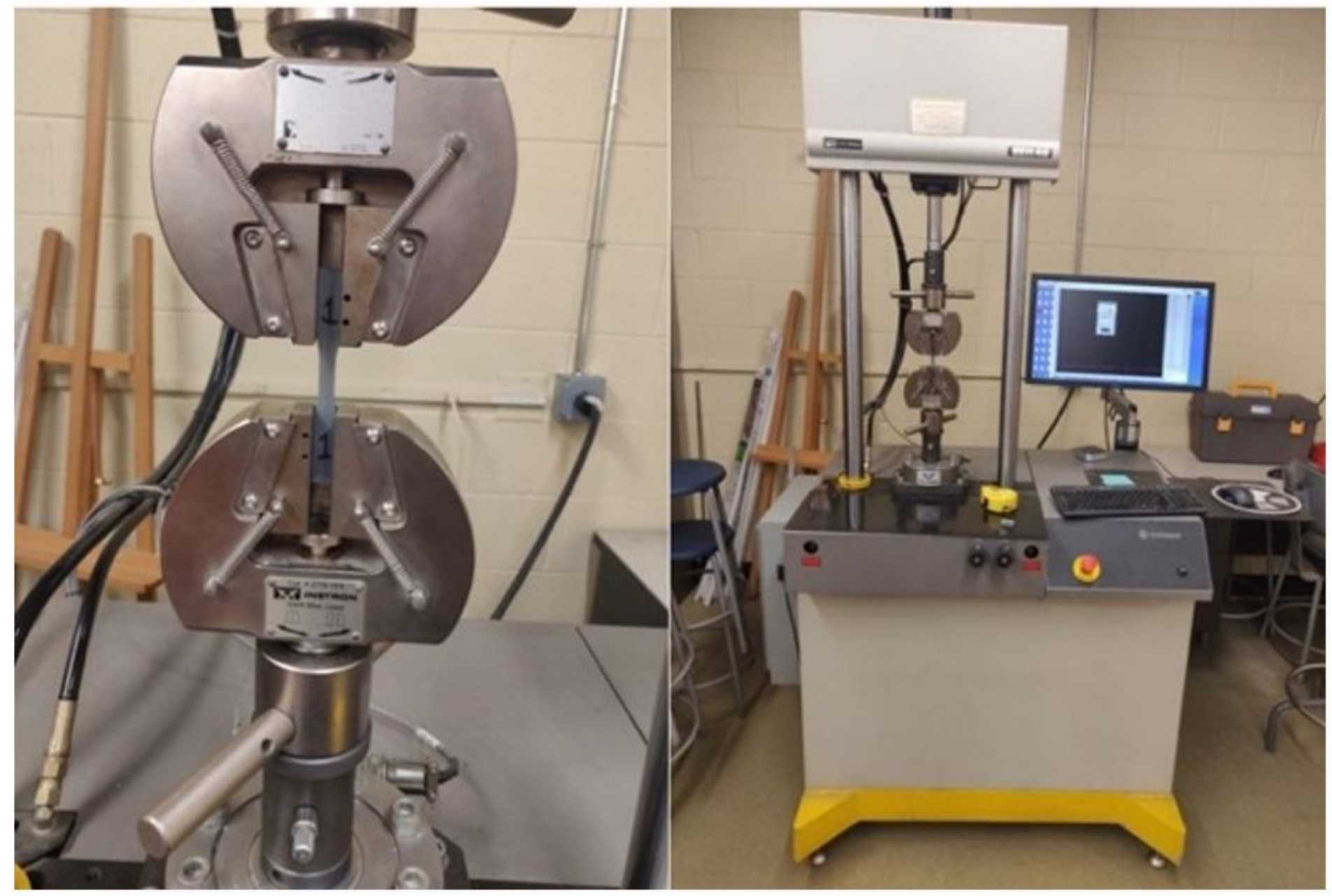

Figure 4

Instron tensile strength tester 


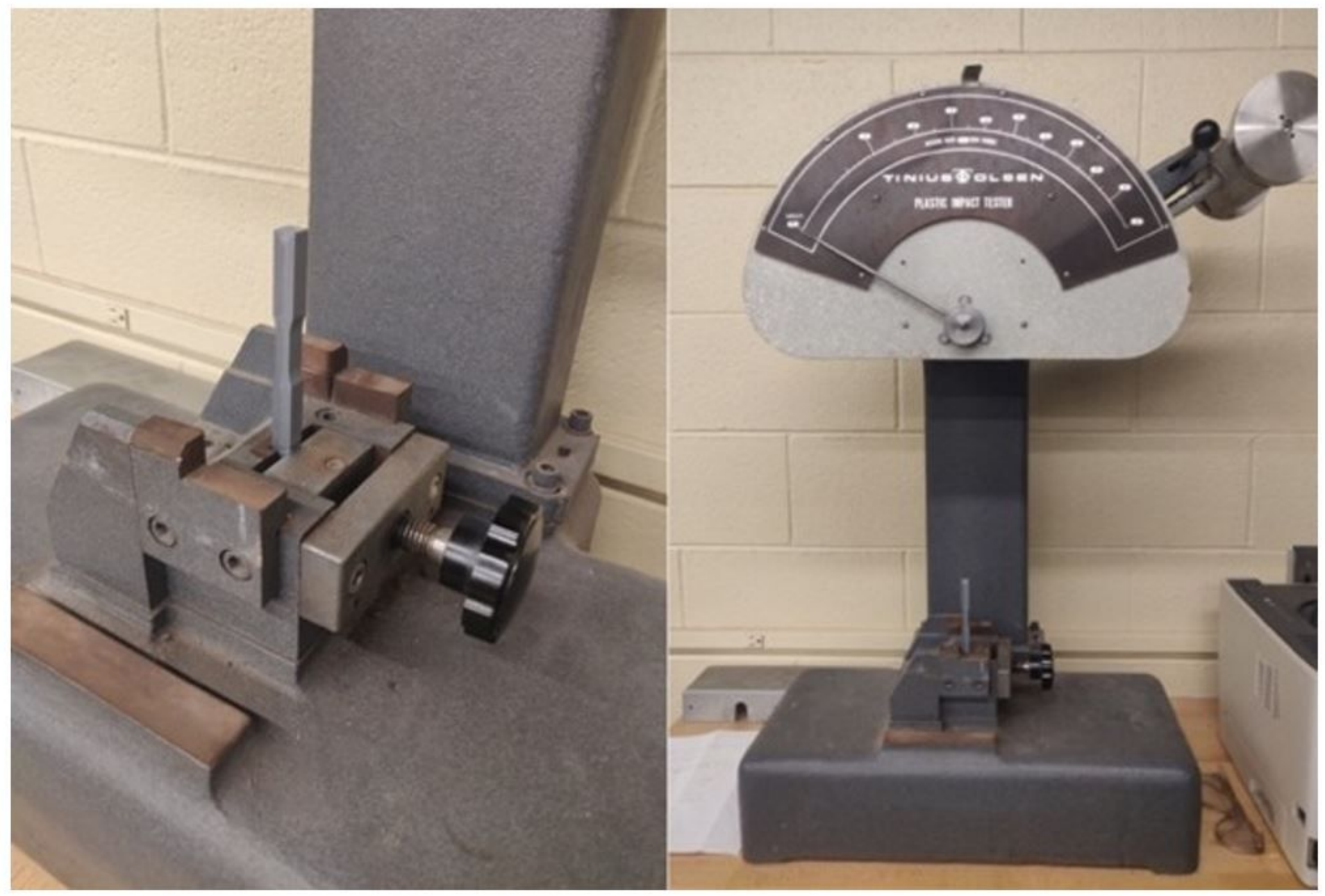

\section{Figure 5}

Tinius Olsen Izod impact tester 


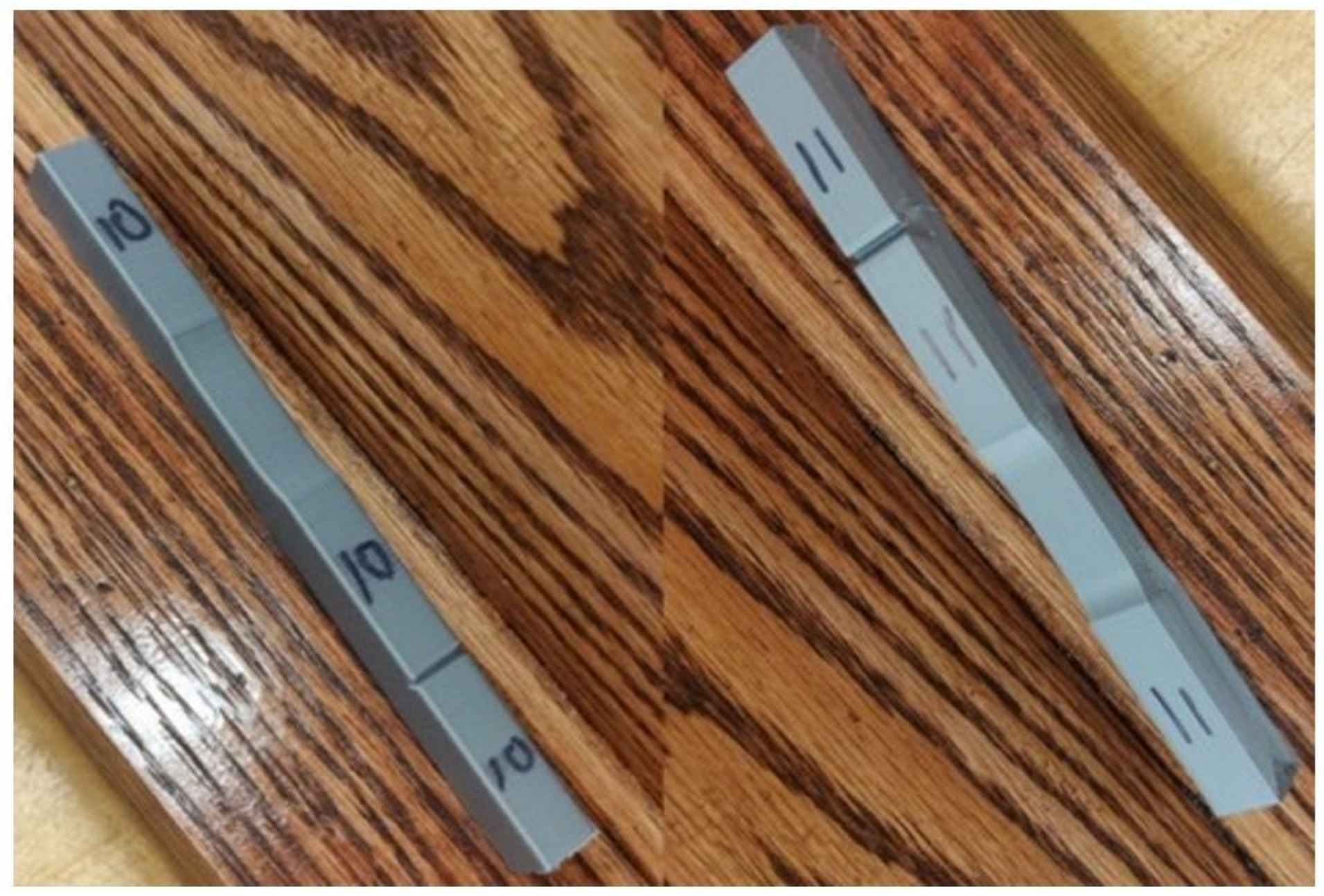

\section{Figure 6}

Vertical Versus Horizontal Orientation Sample. Vertical orientation Left, Horizontal orientation Right 


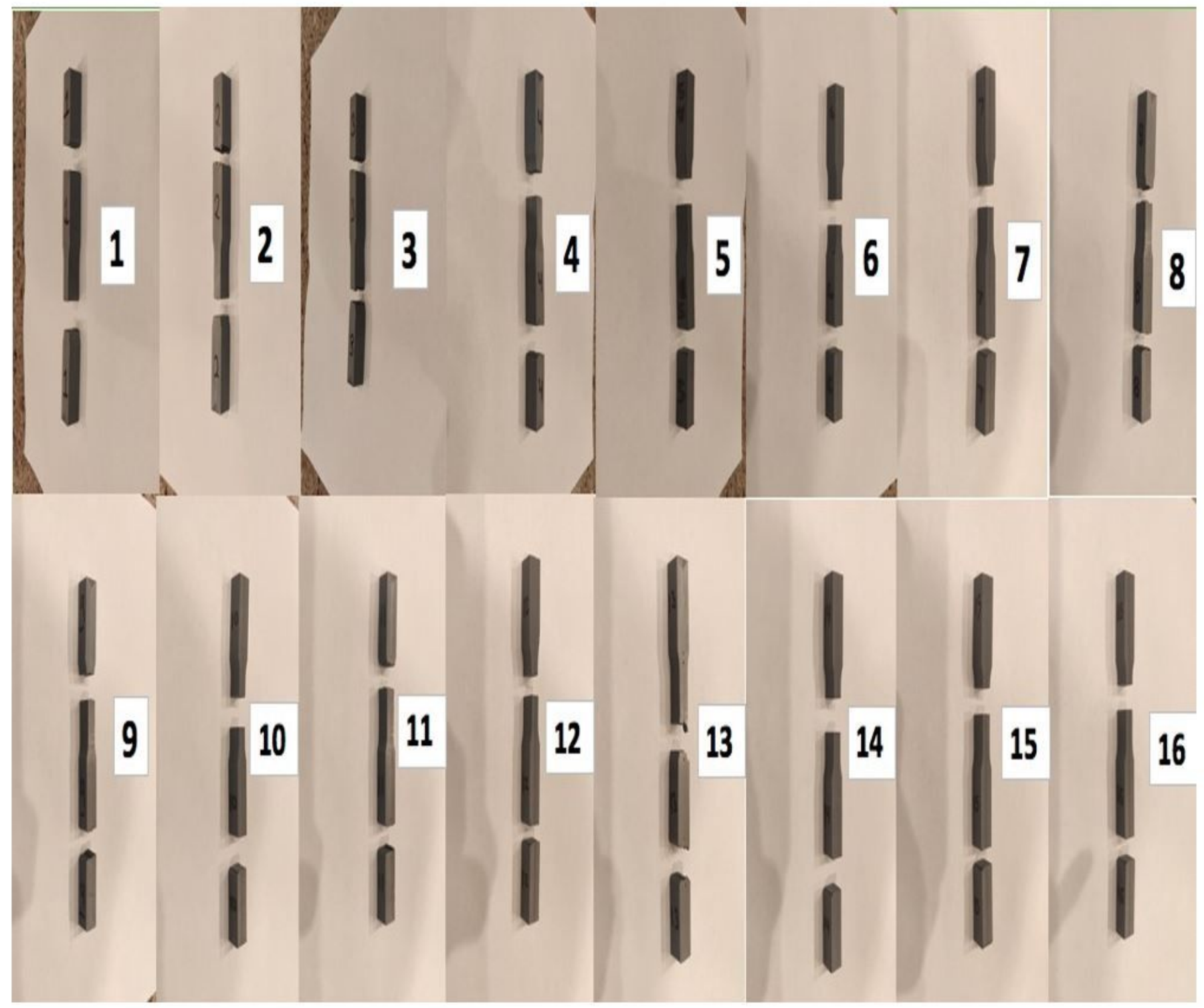

Figure 7

All test samples after the tensile strength and toughness testing

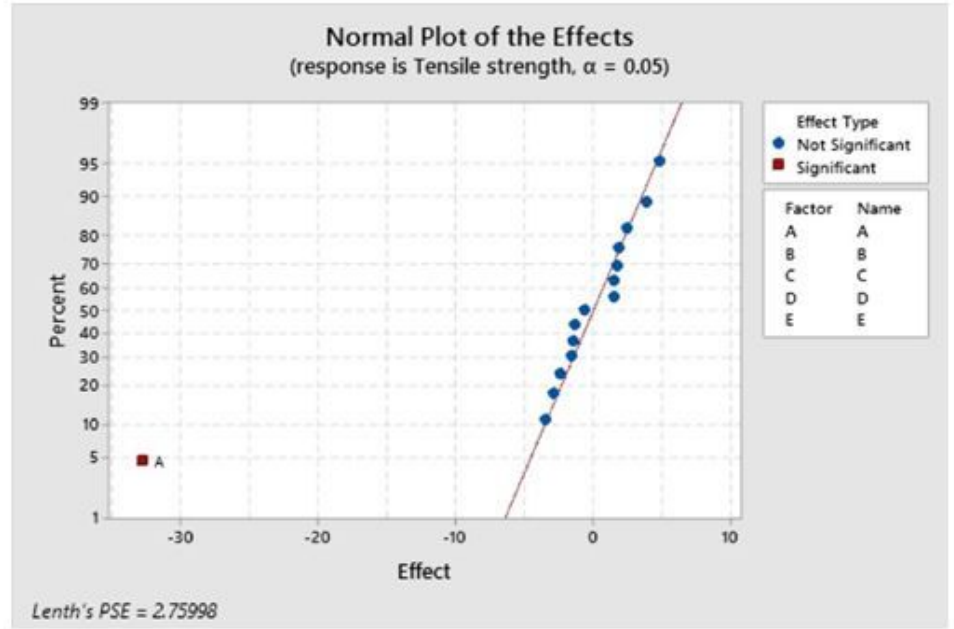

(a)

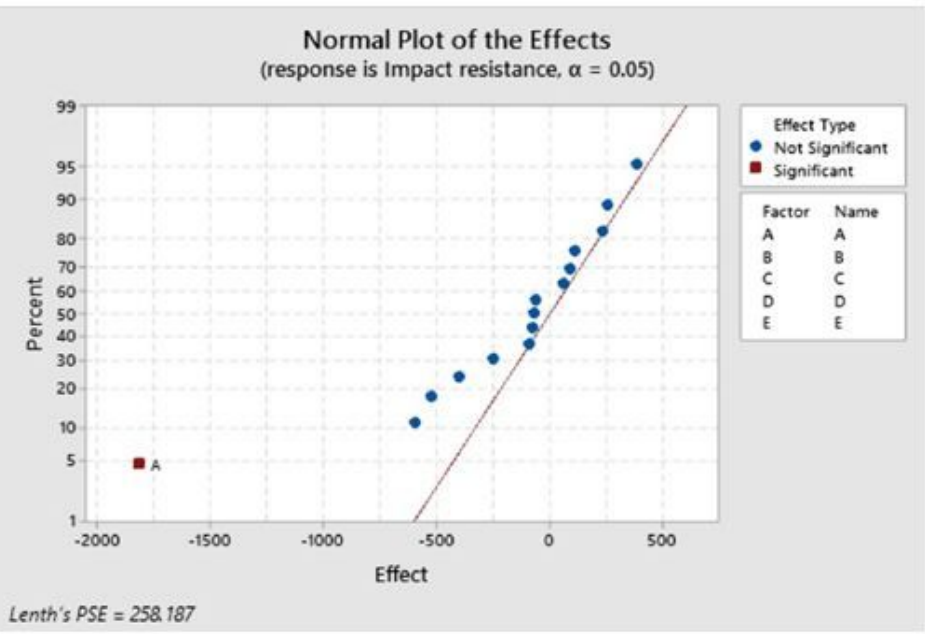

(b) 


\section{Figure 8}

Normal Probability Plot for (a) UTS's effect and (b) impact toughness's effect

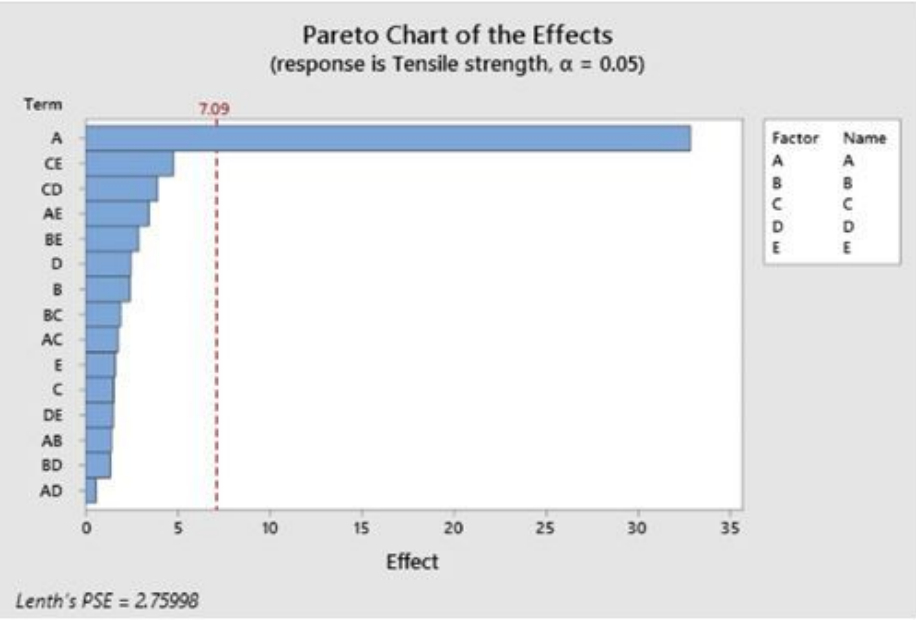

(a)

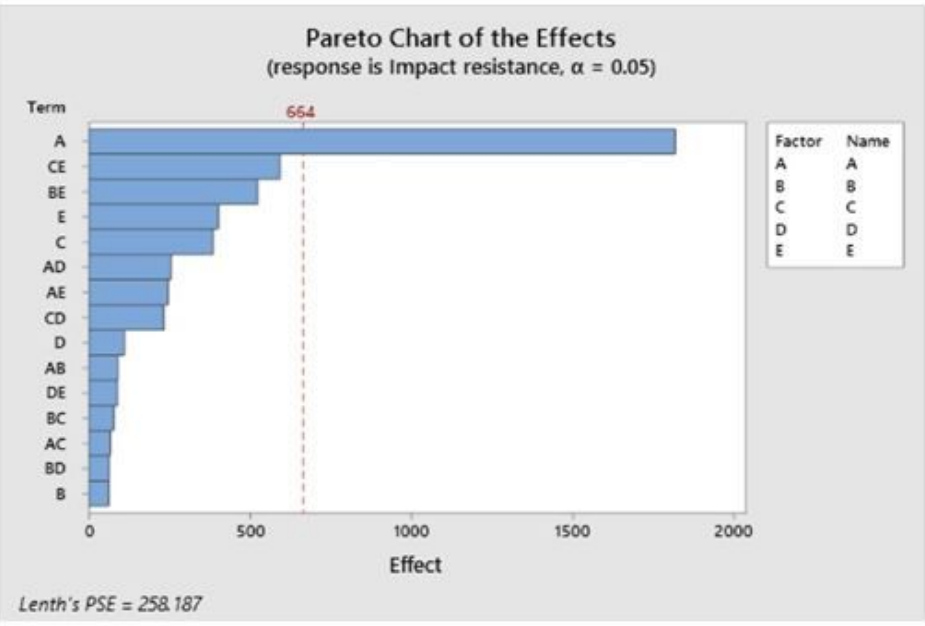

(b)

\section{Figure 9}

Pareto chart of (a) ultimate tensile strength and (b) impact toughness

\section{Normal Probability Plot (response is Tensile strength)}

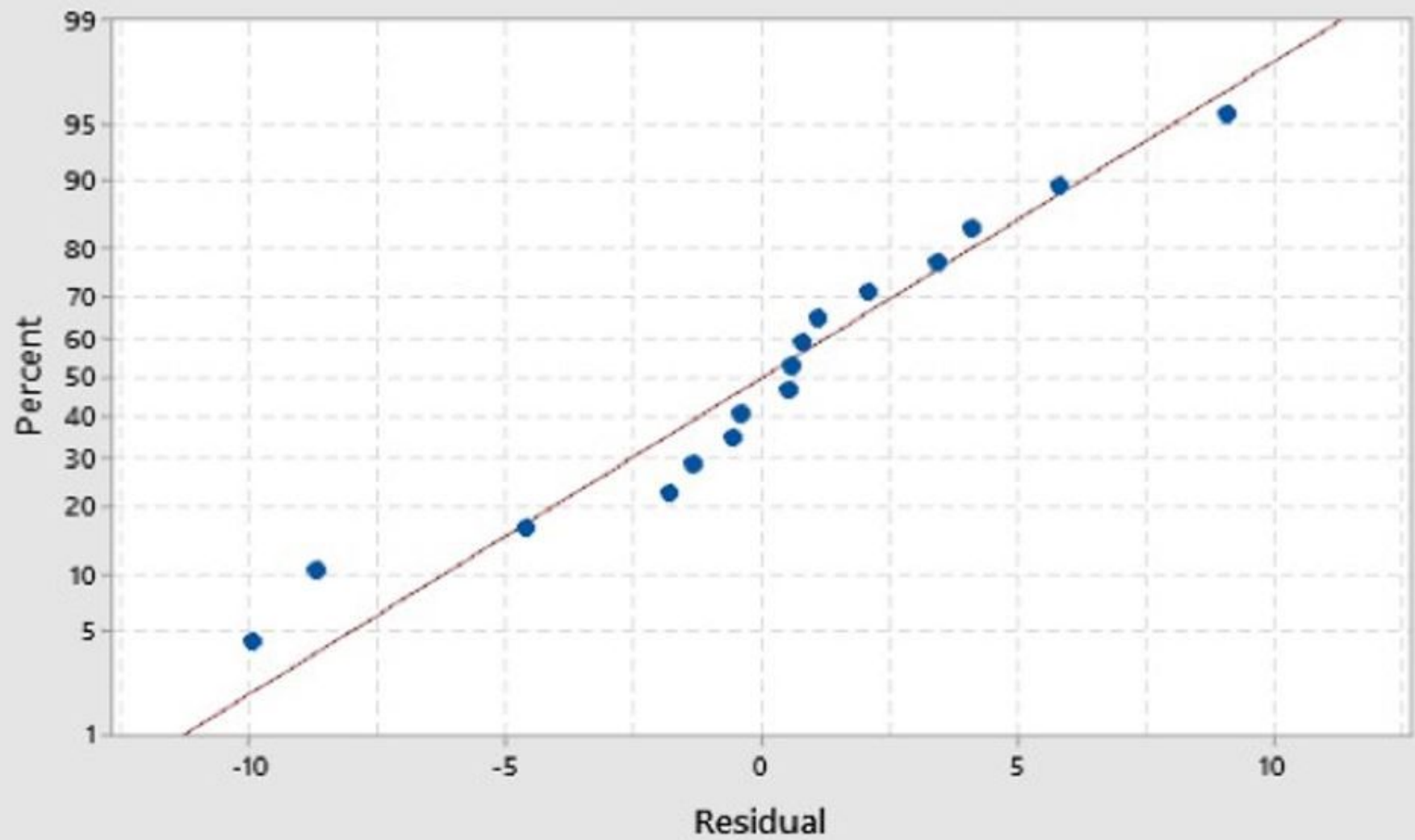


Normal Probability Plot for UTS's residuals

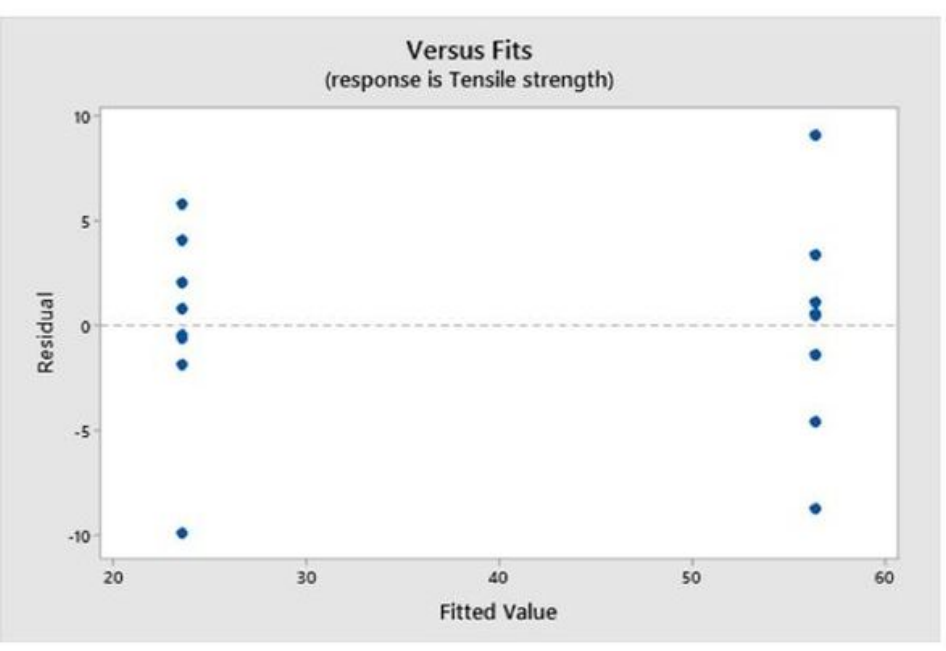

(a)

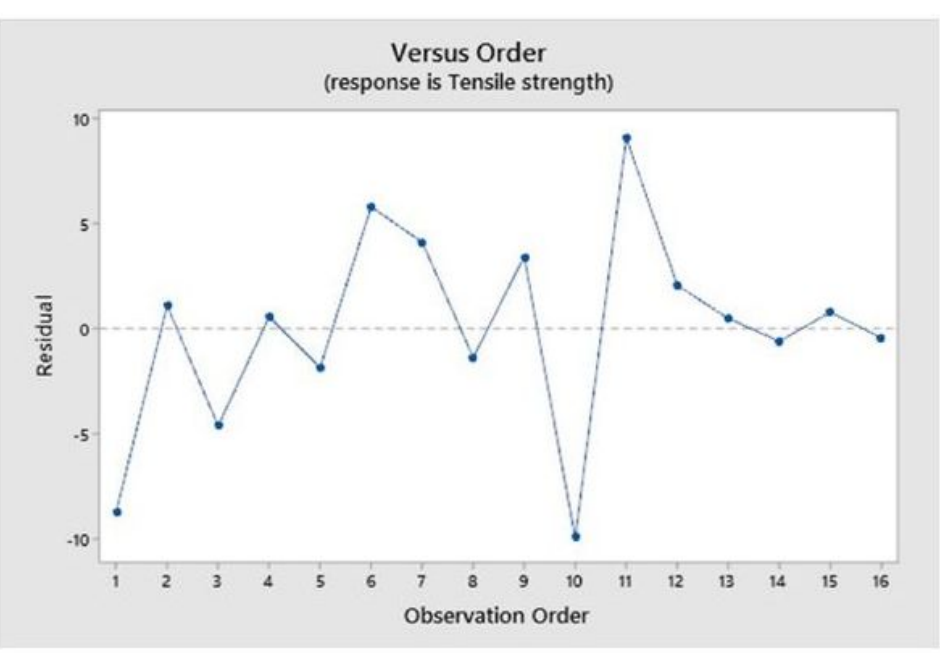

(b)

\section{Figure 11}

Plot of UTS's residuals versus (a) fitted values and (b) observation order

\section{Normal Probability Plot (response is Impact resistance)}

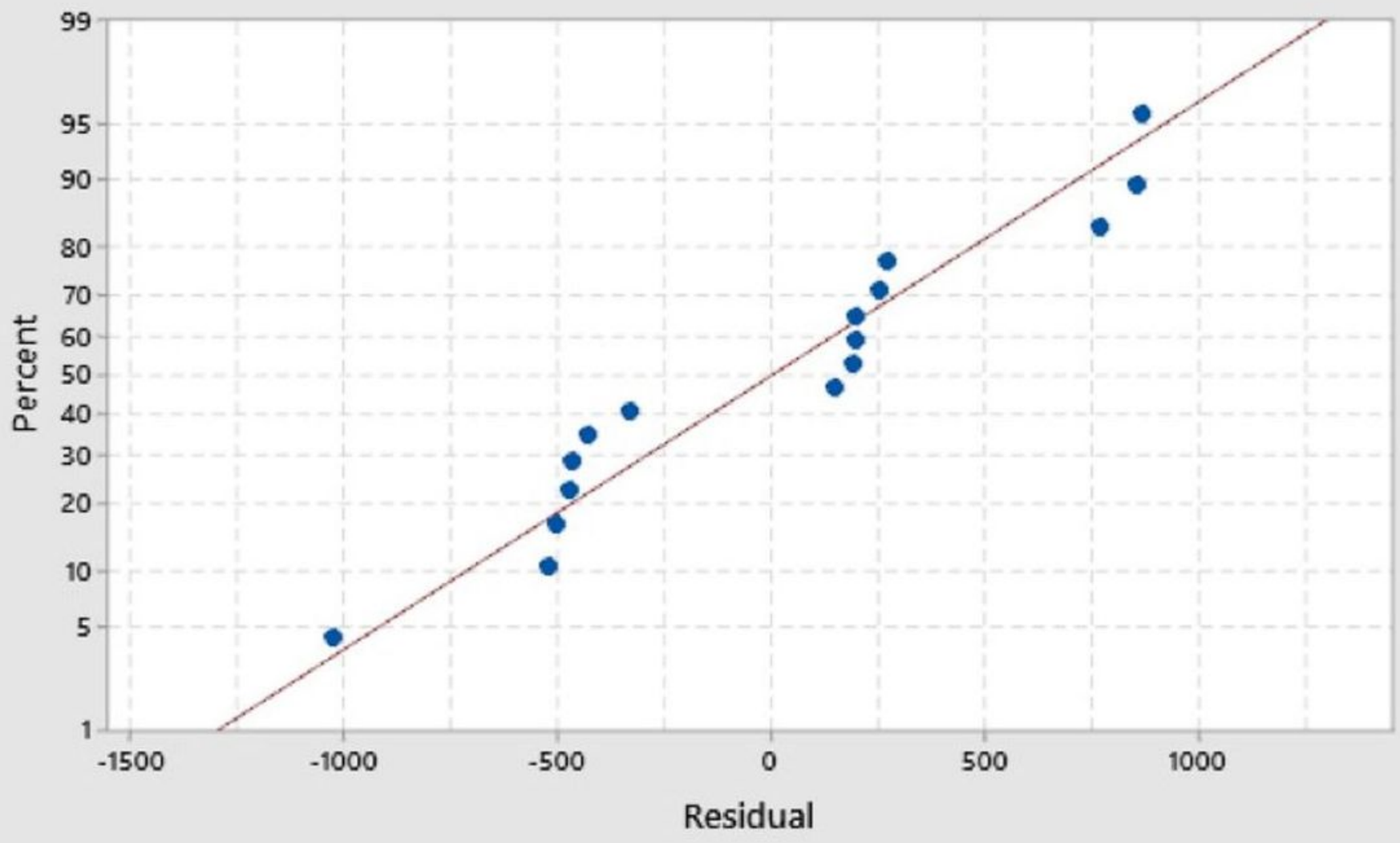

Figure 12

Normal Probability Plot for impact toughness's residuals 


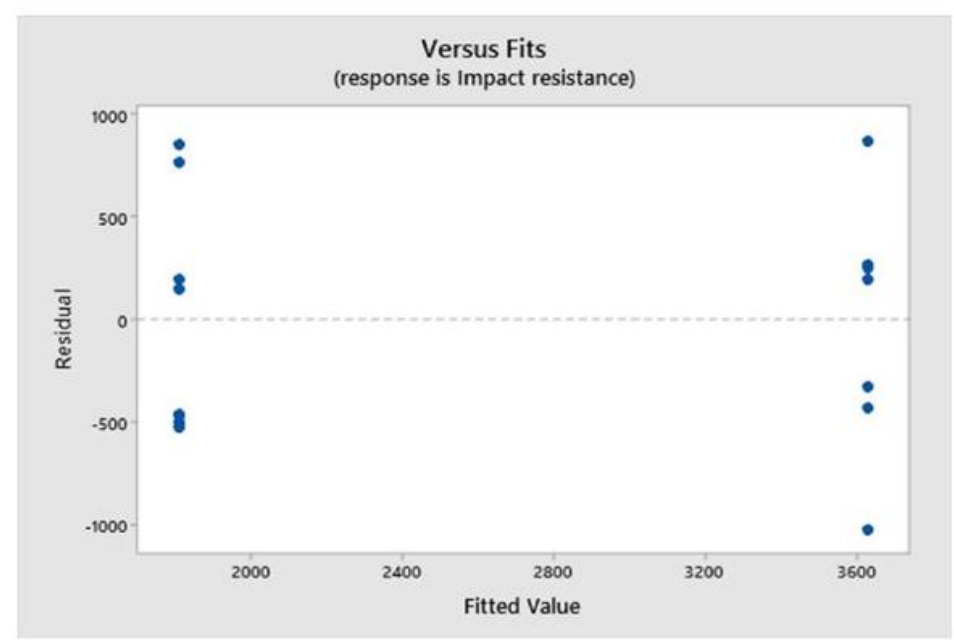

(a)

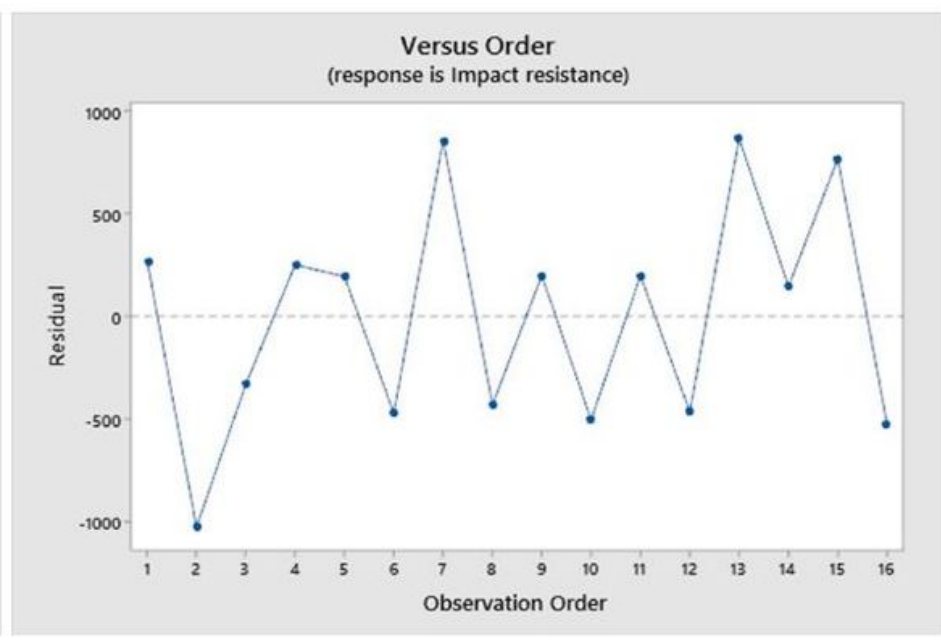

(b)

Figure 13

Plot of toughness's residuals versus (a) fitted values and (b) observation order 